\title{
Pattern, Trend and Predictors of Adult- Onset Type 1 Diabetes in Uyo, Nigeria
}

\author{
Collins Amadi $^{a}$ Olufisayo G. Ayoade ${ }^{a}$ Samuel I. Onung ${ }^{b}$ Sarah I. Essien ${ }^{c}$ \\ Anietie A. Etuk ${ }^{a}$ Chidozie J. Okafor ${ }^{a}$ \\ aDepartment of Chemical Pathology, University of Uyo Teaching Hospital, Uyo, Nigeria; ${ }^{b}$ Endocrinology Unit, \\ Department of Internal Medicine, University of Uyo Teaching Hospital, Uyo, Nigeria; 'Department of Chemical \\ Pathology, University of Uyo, Uyo, Nigeria
}

\section{Keywords}

Diabetes · Type 1 diabetes · Adult-onset type 1 diabetes

\begin{abstract}
Background: Unlike what obtains in childhood-onset type 1 diabetes, there remains a paucity of data on adult-onset type 1 diabetes in Nigeria. Hence, the current study aimed to determine the general characteristics of adult-onset type 1 diabetes among subjects (aged $\geq 18$ years) presenting at the University of Uyo Teaching Hospital (UUTH) in Akwa Ibom State, South-south Nigeria. Methods: A 5-year (2014-2018) retrospective records review of subjects with type 1 diabetes was undertaken, using hospital medical records retrieved from the Department of Health Information Management of UUTH. Diagnosed adult cases of type 1 diabetes were meticulously identified and the relevant data at the point of initial diagnosis were acquired on a specially designed data acquisition template. Results: A total of 47,357 medical cases were identified of which 362 adults were diagnosed with type I diabetes (mean age 33.12 \pm 4.40 , range $20-51$ years) and the females ( $n=204 ; 56.4 \%$ ) predominated among those diagnosed. The overall, male gender, and female gender prevalence was $7.4 / 1,000$ (95\% confidence interval [Cl]: 6.89-7.98), 3.3/1,000 (95\% Cl: 2.52-4.08), and 4.3/1,000 (95\% Cl: 3.61-4.99), respectively. The females exhibited the high-
\end{abstract}

karger@karger.com www.karger.com/dde

Karger $\stackrel{\text { ' }}{5}$

GOPEN ACCESS
(C) 2020 The Author(s)

Published by S. Karger AG, Basel

This article is licensed under the Creative Commons AttributionNonCommercial-NoDerivatives 4.0 International License (CC BYNC-ND) (http://www.karger.com/Services/OpenAccessLicense). Usage and distribution for commercial purposes as well as any distribution of modified material requires written permission. est trough, peak, annual, and overall prevalence during the study period. The female gender (OR: $2.334 ; 95 \% \mathrm{Cl}: 1.407-$ $3.478 ; p=0.010$ ), age $\leq 30$ years (OR: $1.976 ; 95 \% \mathrm{Cl}: 0.875-$ $3.211 ; p<0.001$ ), urban-dwelling (OR: 3.243; 95\% Cl: $2.3407 .780 ;<0.001$ ), diabetes family history (OR: 1.365; 95\% Cl: $0.678-2.010 ; p=0.033)$, and the rainy season (OR: 1.129; $95 \% \mathrm{Cl}: 0.401-1.910 ; p<0.001)$ were independent predictors among the overall adult type 1 diabetics. On gender-segregated analyses, age $\leq 30$ years, urban-dwelling, diabetes family history, and the rainy season remained independent predictors among the male and female adult type 1 diabetics $(p<0.05)$. Conclusion: The study demonstrated a high burden of type 1 diabetes among adult residents of Uyo, Akwa Ibom State, South-South Nigeria. The predictors of adult type 1 diabetes, identified in the present study, are valuable epidemiologic evidence for the design of type 1 diabetestargeted preventive programs by various concerned stakeholders.

(c) 2020 The Author(s)

Published by S. Karger AG, Basel

\section{Introduction}

Epidemiologic evidence on the global pattern and rising trend of diabetes mellitus indicate a pandemic dimension of the metabolic disorder. Projections in the next few 
decades by various recognized authorities are alarming with $>600$ million predicted to be diagnosed by 2040 [1]. These projections cut across the major diabetes types including type 1 , type 2 , and gestational diabetes mellitus, with these predictions disproportionately more calamitous among the low- to medium-income nations of the world [2].

While Type 2 diabetes and gestational diabetes are characterized by resistance to insulin action and suboptimal insulin secretory response, type 1 diabetes is a heterogeneous disorder associated with the destruction of pancreas beta cells, with the resultant effect of absolute insulin deficiency $[3,4]$. The etiology of type 1 diabetes ranges from autoimmune-mediated destruction of beta cells (1A) to idiopathic destruction/failure of the beta cells (1B) [3, 4]. Nevertheless, type 2 diabetes remains the most common adult diabetes accounting for $90-95 \%$ of reported global diabetes burden [1-3].

Research findings widely perceive that the rising trend of type 2 diabetes is responsible for the current dangerous transition of global diabetes epidemiology [2-4]. However, type 1 diabetes, which accounts for $5-10 \%$ of the global diabetes burden, has also been suggested of exhibiting same epidemiologic pattern and trend as type 2 diabetes [5]. A recent report had documented a worldwide increase in the incidence of adult-onset type 1 diabetes by as much as $2-5 \%$ per annum [6]. Although type 1 diabetes is adjudged the most common diabetes type reported among children and adolescence, adults constitute about $85 \%$ of those diagnosed with the metabolic disorder [7].

There is a dearth of literature on adult-onset type 1 diabetes in Nigeria. Besides, most of the known data on adult-onset diabetes in Nigeria have largely focused on either type 2 diabetes or diabetes types 1 and 2 concurrently without segregation.

Currently, the South-South region of Nigeria is believed to have the highest prevalence of diabetes in the country, and the urban city of Uyo is in the heart of the South-South region of the country [8]. However, to date, no data exist on adult-onset type 1 diabetes in the urban city of Uyo. Hence, the current study aimed to highlight the pattern, trend, and the predictors by gender of adult type 1 diabetes in the urban city of Uyo, Nigeria.

\section{Materials and Methods}

\section{Study Design and Site}

The study was a hospital-based retrospective records review of adult cases of type 1 diabetes over 5 years at the University of Uyo Teaching Hospital (UUTH). UUTH is a tertiary medical facility located in Akwa Ibom State, South-South region of Nigeria. It is a major referral center for both the private, primary, and secondary healthcare facilities in the state and its adjoining states.

\section{Ethical Considerations}

Approval for the study was obtained from the Research Ethics Committee of the hospital and the study was conducted in accordance with the principles of the Helsinki Declaration as revised in 2008. Written informed consent was not deemed necessary owing to the retrospective nature and solely data-based design of the study. However, the confidentiality of the subjects was adequately maintained during the data acquisition protocols in compliance with the UUTH Research Ethics standard.

\section{Study Instruments and Populations}

The study instrument was only hospital data, obtained from the Department of Health Information Management, of all the eligible adults diagnosed with type 1 diabetes in the UUTH.

\section{Data Acquisition Protocols}

Data was acquired from the medical files using trained research assistants. First, medicals files of all the medical cases managed during the study period were identified and counted. Secondly, the files of the diabetic cases were carefully sorted out. Thirdly, the files of the type 1 diabetics were carefully extracted and confirmed using the relevant registers. Finally, all relevant specific data, at type 1 diagnosis, were abstracted which included age, sex, educational and marital status, areas of residence, occupation, family history of diabetes, alcohol/cigarette consumption history, systolic/diastolic blood pressures, BMI, month and year diagnosed. Wellstructured pro forma with columns under the aforementioned variable headings was employed for data acquisition.

\section{Eligibility Criteria}

Criteria for inclusion were eligible medical records of all patients diagnosed with adult-onset ( $\geq 18$ years of age) type 1 diabetes in UUTH during a 5-year period (January 1, 2014, to December $31,2018)$. Criteria for exclusion were records of those with incomplete data, records of those $<18$ years old, pregnant cases, and those diagnosed outside the study period (2014-2018).

\section{Laboratory Protocols}

During the study period, all specimen collection and laboratory protocols had been done following standard protocols. Fasting plasma glucose and random plasma glucose were determined using the glucose oxidase/peroxidase principle in fluoridated plasma. Glycated hemoglobin AIc was determined via the immunoturbidimetric principle with whole blood specimen in ethylenediamine-tetra-acetic specimen tubes. Laboratory analyses were carried out on Selectra Pro M (ELITech Grp, Spankeren, The Netherlands) automated chemistry analyzer.

\section{Laboratory Diagnosis}

During the period under study, laboratory diagnosis of adultonset type 1 diabetes was based on the 1999 World Health Organization and the 2010 American Diabetes Association diagnostic criteria $[3,4]$.

1. Based on the 1999 World Health Organization diagnostic criteria, adult-onset type 1 diabetes was diagnosed if at least any one of the following laboratory parameters is obtained among 
Table 1. Prevalence of adult-onset type 1 diabetes in UUTH during 2014-2018

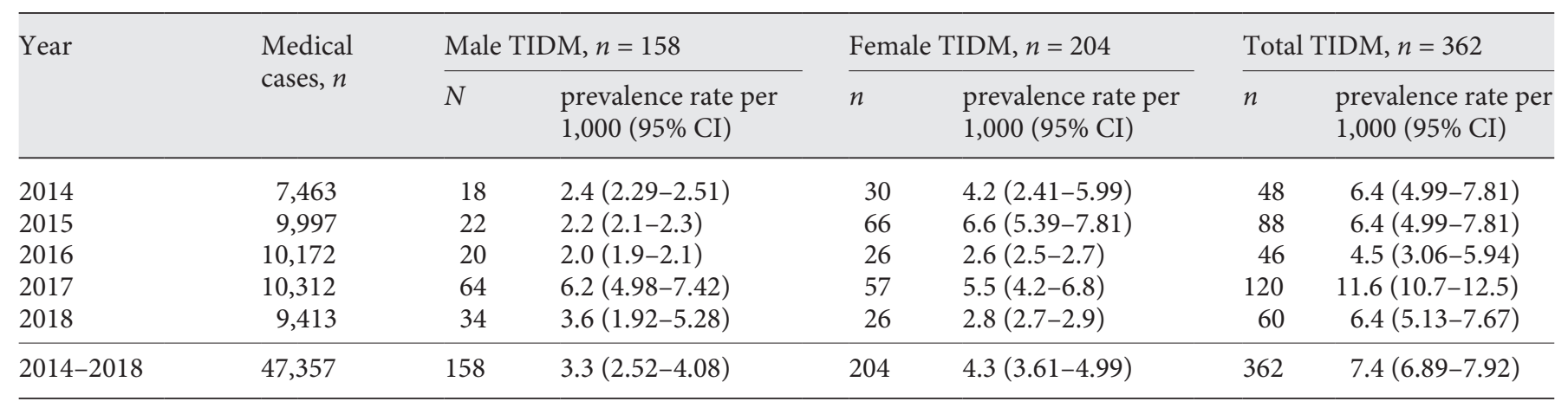

UUTH, University of Uyo Teaching Hospital; TIDM, Type 1 diabetes mellitus; CI, confidence interval.

the suspected cases: (1) fasting plasma glucose $\geq 7.0 \mathrm{mmol} / \mathrm{L}$, (2) random plasma glucose $\geq 11.1 \mathrm{mmol} / \mathrm{L}$, and (3) two-hour OGTT $\geq 11.1 \mathrm{mmol} / \mathrm{L}$.

2. Based on the 2010 American Diabetes Association diagnostic criteria, adult-onset type 1 diabetes was diagnosed if glycated hemoglobin AIc level is $\geq 6.5 \%$ among any suspected case.

\section{Operational Definitions}

1. a. Diagnosed in UUTH during 2014-2018 and currently being managed for 2 years or more at the time of data acquisition by the specialist endocrinologist in the study center. b. Persistently on insulin therapy since type 1 diabetes diagnosis. c. Nil history of oral hypoglycemic medications since type 1 diabetes diagnosis and/or no response to any oral hypoglycemic medications since type 1 diabetes diagnosis d. Aged $\geq 18$ years old.

2. Seasons were defined as dry (months of November-March) and rainy (months of April-October) seasons based on Southern Nigerian climate expression.

3. Educational status was stratified as low (no formal education, primary, and secondary) or high (tertiary education), while occupational status was defined as low (students, petty traders, retired civil and public servants, others - daily laborer, hairstylist, car mechanic, and unemployed) or high (businessmen/ women, current civil and public servants)

\section{Data Management and Statistical Analysis}

Data was initially keyed into Statistical Package for Social Sciences version 21 (IBM Corp., Armonk, NY, USA). The noncategorical variables were evaluated for distribution patterns using the Shapiro-Wilk test. Those found not to be of normal distribution were subsequently log-transformed before analysis. Noncategorical variables are presented as means and standard deviations, with comparisons conducted using Student's $t$ tests. The categorical variables are summarized using proportions expressed as numbers and frequencies; between-group comparisons were performed using Pearson $\chi^{2}$ tests with continuity correction applied when necessary or using the Fisher's exact test where appropriate.

Binary logistic regression was used to determine the predictors of type 1 diabetes in the univariate analyses and the variables showing statistical significance in the univariate analysis were further tested in the multivariate analyses. The prevalence rates, obtained by dividing the number of diabetic cases as the numerator by the total number of the medical cases as the denominator, was expressed per 1,000 at 95\% confidence intervals (CIs). The CIs for the prevalence estimate was calculated using the following formula $(95 \% \mathrm{CI}=$ prevalence $\pm 1.96 \times$ standard error $)$ [9]. Two-tailed $p<0.05$ values were considered statistically significant.

\section{Results}

During the study period (2014-2018), a total of 47,357 in-patient and out-patient medical cases were managed in the study center. Of the total medical cases, 2,560 (5.4\%) were diagnosed with DM. Following the review of the diabetic medical records, 2,198 were identified as type 2 diabetes ( $85.9 \%)$, while $362(14.1 \%)$ were identified as adult-onset type 1 diabetics.

The females predominated among those diagnosed with adult-onset type 1 diabetes during the 2014-2018 period compared to the males (females: $n=204 ; 56.40 \%$ vs. males: $n=154 ; 43.60 \%$; $p=0.016$ ) with male/female ratio of 0.77 . Shown in Table 1 , the total type 1 diabetes prevalence in both sexes declined in $2016(4.5 / 1,000)$ from 2014 and spiked in $2017(11.7 / 1,000)$ with an overall prevalence of 7.4/1,000 during the 2014-2018 period. Among the males, type 1 diabetes prevalence also exhibited a trough in $2016(2.0 / 1,000)$ and also attained its peak in $2017(6.2 / 1,000)$ with an overall prevalence of $3.3 / 1,000$. While among the females, type 1 diabetes prevalence also exhibited a trough in $2016(2.6 / 1,000)$; however, it peaked in $2017(6.6 / 1,000)$ with an overall prevalence of $4.3 / 1,000$. Hence, compared to the males, females exhibited the highest trough, peak, annual, and overall type 1 diabetes prevalence rate during the 2014-2018 period. 
Table 2. Age/clinical characteristics of the study cohorts at type 1 diabetes diagnosis

\begin{tabular}{|c|c|c|c|c|}
\hline Variables & $\begin{array}{l}\text { Male TIDM, } \\
n=158\end{array}$ & $\begin{array}{l}\text { Female TIDM, } \\
n=204\end{array}$ & $p$ value & $\begin{array}{l}\text { Total TIDM, } \\
n=362\end{array}$ \\
\hline \multicolumn{5}{|c|}{ Age at onset, years } \\
\hline Mean \pm SD & $34.24 \pm 5.20$ & $32.25 \pm 5.70$ & $<0.001^{*, \mathrm{a}}$ & $33.12 \pm 4.40$ \\
\hline Range & $(23-41)$ & $(20-51)$ & & $(20-51)$ \\
\hline \multicolumn{5}{|c|}{ Age-groups, years, $n(\%)$} \\
\hline $18-29$ & $38(24.1)$ & $86(42.2)$ & $<0.001^{*, \mathrm{~b}}$ & $124(34.3)$ \\
\hline $30-39$ & $80(50.6)$ & $92(45.1)$ & & $172(47.5)$ \\
\hline $40-49$ & $40(25.3)$ & $18(8.8)$ & & $58(16.0)$ \\
\hline $50-59$ & $0(0.0)$ & $8(3.8)$ & & $8(2.25)$ \\
\hline$>60$ & $0(0.0)$ & $0(0.0)$ & & $0(0.0)$ \\
\hline $\mathrm{SBP}, \mathrm{mm} \mathrm{Hg}$ & $119.65 \pm 7.35$ & $119.90 \pm 9.26$ & 0.069 & $119.20 \pm 8.40$ \\
\hline $\mathrm{DBP}, \mathrm{mm} \mathrm{Hg}$ & $79.85 \pm 6.60$ & $80.10 \pm 9.20$ & 0.190 & $78.10 \pm 7.61$ \\
\hline BMI, $\mathrm{kg} / \mathrm{m}^{2}$ & $24.94 \pm 3.60$ & $26.30 \pm 4.25$ & $0.017^{*, \mathrm{~b}}$ & $24.27 \pm 3.4$ \\
\hline
\end{tabular}

TIDM, Type 1 diabetes mellitus; SD, Standard deviation. * Statistically significant. ${ }^{\text {a }}$ Student $t$ test. ${ }^{\mathrm{b}}$ Fisher's exact test

In Table 2, the mean age at diagnosis of the overall sample was $33.12 \pm 4.40$ (range $20-51$ ). The females presented at younger mean age than the males (female 32.25 \pm 5.70 vs. male $34.24 \pm 5.20 ; p<0.001$ ). The majority $(n=86 ; 42.2 \%)$ of the females presented before the age of 30 years compared to the males $(n=38 ; 24.1 \%)$. Most ( $n=172 ; 47.5 \%)$ of the type 1 diabetics were in the $30-39$ age bracket (Table 2 ), with similar trend observed among the males $(n=80 ; 50.6 \%)$ and females $(n=92 ; 45.1 \%)$.

As depicted in Table 3, most of the type 1 diabetes subjects who were mostly resident in the urban centers, married and engaged in petty trading at the time of diagnosis, and the females predominated among this group. Additionally, most of the type 1 diabetes subjects had attained tertiary educational status and affirmed to a family history of diabetes $(n=85 ; 23.5 \%)$ with the males predominating among this group (Table 3 ).

The females predominated among those who are present drinkers while the males predominated among those who are present smokers. The majority of the total subjects $(n=245 ; 67.7 \%)$, the male $(n=113: 71.5 \%)$, and female $(n=132 ; 64.7 \%)$ type 1 diabetics were diagnosed during the rainy season (Table 3 ).

Depicted in Table 4, the female gender (OR: 2.317; 95\% CI: $0.846-4.117 ; p=0.016$ ), age $\leq 30$ years (OR: 2.549; 95\% CI: $1.574-3.463 ; p<0.001)$, urban-dwelling (OR: 3.553; 95\% CI: 2.617-4.410; $p=0.009$ ), diabetes family history (OR: 1.843; 95\% CI: 0.798-2.736; $p=$ 0.024 ), and rainy season (OR: 1.563 ; 95\% CI: $0.987-$ $1.117 ; p=0.003$ ) were predictors of adult-onset type 1 diabetes among the overall cohorts on univariate analyses.

On multivariate analyses, the female gender (OR: 2.334; 95\% CI: $1.407-3.478 ; p=0.010$ ), age $\leq 30$ years (OR: 1.976; 95\% CI: $0.875-3.211 ; p<0.001)$, urban-dwelling (OR: 3.243; 95\% CI: 2.340-7.780; $p<0.001$ ), diabetes family history (OR: $1.365 ; 95 \%$ CI: $0.678-2.010 ; p=0.033$, and rainy season (OR: $1.129 ; 95 \%$ CI: $0.401-1.910 ; p<0.001$ ) remained independent predictors of adult-onset type 1 diabetes (Panel A, Table 4). This predictive pattern was also obtained separately among the males and females (Panel A, Table 4). The independent predictive potentials of age $\leq 30$ years $($ male $=$ OR: $1.677 ; p<0.001$ vs. female $=$ OR: $2.321 ; p<0.001$ ), urban-dwelling (male = OR: 1.389; $p=0.006$ vs. female $=$ OR: $2.137 ; p<0.001)$, diabetes family history (male $=$ OR: $1.187 ; p$ : 0.004 vs. female $=$ OR: 2.456; $p: 0.015$ ), and rainy season (male $=$ OR: $1.464 ; p<$ 0.001 vs. female $=$ OR: $1.511 ; p<0.001)$ were more pronounced among the females than the males (Panel B, Table 4).

\section{Discussion}

Between 2014 and 2018, the total (male and female), male gender, and female gender type 1 diabetes prevalence fluctuated with women exhibiting the highest annual, trough, and peak prevalence rates compared to the males during each of the 5 -year periods. The dynamic fluctuations in these prevalence rates, observed in the 
Table 3. Other sociodemographic characteristics of study cohorts

\begin{tabular}{|c|c|c|c|c|}
\hline Variables & $\begin{array}{l}\text { Male TIDM, } \\
n=158\end{array}$ & $\begin{array}{l}\text { Female TIDM, } \\
n=204\end{array}$ & $p$ value & $\begin{array}{l}\text { Total TIDM, } \\
n=362\end{array}$ \\
\hline \multicolumn{5}{|l|}{ Place of residence, $n(\%)$} \\
\hline Urban & $80(50.6)$ & $126(61.8)$ & \multirow[t]{2}{*}{$0.034^{*, \mathrm{a}}$} & $206(56.9)$ \\
\hline Rural & $78(49.4)$ & $78(38.2)$ & & $156(43.1)$ \\
\hline \multicolumn{5}{|l|}{ Union status, $n(\%)$} \\
\hline Married & $114(72.2)$ & $128(62.7)$ & \multirow[t]{4}{*}{$<0.001^{*, \mathrm{~b}}$} & $242(66.9)$ \\
\hline Single & $44(27.8)$ & $66(32.4)$ & & $110(30.4)$ \\
\hline Bereaved & - & $6(2.9)$ & & $6(1.7)$ \\
\hline Separated & - & $4(2.0)$ & & $4(1.1)$ \\
\hline \multicolumn{5}{|l|}{ Educational status, $n(\%)$} \\
\hline Primary & $10(6.3)$ & $10(4.9)$ & \multirow[t]{4}{*}{$<0.001^{*, \mathrm{~b}}$} & $20(5.5)$ \\
\hline Secondary & $22(13.9)$ & $120(58.8)$ & & $142(39.2)$ \\
\hline Tertiary & $122(77.2)$ & $72(35.3)$ & & $194(53.6)$ \\
\hline No formal education & $4(2.5)$ & $1(1.0)$ & & $6(1.7)$ \\
\hline \multicolumn{5}{|l|}{ Occupation, $n(\%)$} \\
\hline CS & $52(32.9)$ & $18(8.8)$ & \multirow[t]{7}{*}{$<0.001^{*, \mathrm{~b}}$} & $70(19.3)$ \\
\hline PS & $34(21.4)$ & $22(10.8)$ & & $56(15.3)$ \\
\hline Businessmen/women ${ }^{\mathrm{e}}$ & $10(6.3)$ & $6(2.9)$ & & $16(4.4)$ \\
\hline Petty traders & $32(20.3)$ & $82(40.2)$ & & $114(31.5)$ \\
\hline Retired CS or PS & $4(2.5)$ & $10(4.9)$ & & $14(3.9)$ \\
\hline Student & $26(16.5)$ & $50(24.5)$ & & $76(21.0)$ \\
\hline Others ${ }^{\mathrm{d}}$ & - & $16(7.8)$ & & $16(4.4)$ \\
\hline \multicolumn{5}{|l|}{ Alcohol consumption, $n(\%)$} \\
\hline Never & $137(86.7)$ & $145(71.1)$ & \multirow[t]{3}{*}{$<0.001^{*, \mathrm{c}}$} & $282(77.9)$ \\
\hline Former & $12(7.6)$ & $32(15.7)$ & & $44(12.2)$ \\
\hline Present & $9(5.7)$ & $27(13.2)$ & & $36(9.9)$ \\
\hline \multicolumn{5}{|c|}{ Cigarette consumption, $n(\%)$} \\
\hline Never & $135(85.4)$ & $201(20.1)$ & \multirow[t]{3}{*}{$<0.001^{*, \mathrm{~b}}$} & $336(92.8)$ \\
\hline Former & $17(10.8)$ & $3(1.5)$ & & $20(5.5)$ \\
\hline Present & $6(3.8)$ & $0(0)$ & & $6(1.7)$ \\
\hline \multicolumn{5}{|l|}{ DM family history, $n(\%)$} \\
\hline Positive & $44(27.8)$ & $41(20.1)$ & \multirow[t]{3}{*}{$<0.001^{*, \mathrm{a}}$} & $85(23.5)$ \\
\hline Negative & $103(65.2)$ & $87(42.6)$ & & $190(52.5)$ \\
\hline No available data & $11(7.0)$ & $76(37.3)$ & & $87(24.0)$ \\
\hline \multicolumn{5}{|l|}{ Season of diagnosis, $n(\%)$} \\
\hline Rainy season & $113(71.5)$ & $132(64.7)$ & \multirow[t]{2}{*}{$<0.001^{*, \mathrm{a}}$} & $245(67.7)$ \\
\hline Dry season & $45(38.5)$ & $81(35.3)$ & & $117(22.3)$ \\
\hline
\end{tabular}

TIDM, Type 1 diabetes mellitus; CS, civil servants; PS, public servants. * Statistically significant. ${ }^{\text {a }}$ Chi-square test. ${ }^{b}$ Fisher's exact test. ${ }^{c}$ Chi-square test with Yate's continuity correction. ${ }^{d}$ Daily laborer, hairstylist, car mechanic; unemployed. ${ }^{\mathrm{e}}$ Large-scale.

present sample, could be a consequence of urban-rural migration, environmental, and other unidentified sociocultural factors within the population. However, the overall prevalence during the period was 7.4/1,000 (95\% CI: 6.89-7.98), 3.3/1,000 (95\% CI: 2.52-4.08), and 4.3/1,000 (95\% CI: 3.61-4.99) among the total, male, and female type 1 diabetes subjects, respectively.

To our knowledge, no study had reported genderbased adult-onset type 1 diabetes prevalence in the literature, and there remains a scarcity of data on adult-onset type 1 diabetes as most reports had largely focused on childhood-onset type 1 diabetes or concurrently on type 1 and type 2 diabetes without segregation. In the United States, with the highest type 1 diabetes cases in the world, Menke and colleagues [10] reported 2.6, 1,000 or 3.4, 1,000 prevalence, depending on the 2 defined criteria used in their study, while recently, $\mathrm{Xu}$ and colleagues [11] had reported 5/1,000 (0.5\%) prevalence, without gender segregation in these 2 studies. These previous prevalence rates $(2.6,3.4$, and $5 / 1,000)$ reported among the US adults 
Table 4. LR of predictors of adult-onset TIDM in UUTH during 2014-2018

\begin{tabular}{|c|c|c|c|}
\hline Variable & $\begin{array}{l}\text { Male TIDM } \\
\text { OR (95\% CI); } p \text { value }\end{array}$ & $\begin{array}{l}\text { Female TIDM } \\
\text { OR (95\% CI); } p \text { value }\end{array}$ & $\begin{array}{l}\text { Total TIDM } \\
\text { OR (95\% CI); } p \text { value }\end{array}$ \\
\hline \multicolumn{4}{|l|}{ a Univariate LR } \\
\hline \multicolumn{4}{|l|}{ Gender } \\
\hline Male Reference & - & - & 1.0 \\
\hline Female & - & - & 2.317 (0.846-4.117); 0.016* \\
\hline$\leq 30$ & 1.125 (0.678-1.745); 0.007* & $2.676(1.657-2.337) ;<0.001^{*}$ & $2.549(1.574-3.463) ;<0.001^{*}$ \\
\hline \multicolumn{4}{|l|}{ Place of residence } \\
\hline Rural $^{\text {Reference }}$ & 1.0 & 1.0 & 1.0 \\
\hline Urban & $1.243(1.246-1.768) ;<0.001^{*}$ & 2.843 (1.578-4.179); 0.002* & 3.553 (2.617-4.410); 0.009* \\
\hline \multicolumn{4}{|l|}{ Marital status } \\
\hline Not married ${ }^{\text {Reference }}$ & 1.0 & 1.0 & 1.0 \\
\hline \multicolumn{4}{|l|}{ Educational status } \\
\hline \multicolumn{4}{|l|}{ Occupational status } \\
\hline Low ${ }^{\text {Reference }}$ & 1.0 & 1.0 & 1.0 \\
\hline High & $0.856(0.421-1.495) ; 0.149$ & $0.924(0.342-1.697) ; 0.126$ & $0.918(0.351-1.798) ; 0.067$ \\
\hline \multicolumn{4}{|l|}{ Alcohol ingestion $^{\mathrm{a}}$} \\
\hline Negative $^{\mathrm{R}}$ & 1.0 & 1.0 & 1.0 \\
\hline Positive & $0.331(0.109-581) ; 0.075$ & $0.984(0.451-1.778) ; 0.113$ & 0.967 (0.511-1.780); 0.384 \\
\hline \multicolumn{4}{|l|}{ Cigarette smoking $^{\mathrm{a}}$} \\
\hline Negative Reference & 1.0 & 1.0 & 1.0 \\
\hline Positive & 1.304 (0.571-2.133); 0.093 & $2.341(1.322-3.336) ; 0.112$ & 1.971 (0.588-3.609); 0.634 \\
\hline \multicolumn{4}{|l|}{ DM family history } \\
\hline Negative $^{\text {Reference }}$ & 1.0 & 1.0 & 1.0 \\
\hline Positive & 1.455 (0.633-2.577); 0.041* & $1.747(0.714-3.877) ;<0.001^{*}$ & 1.843 (0.798-2.736); 0.024* \\
\hline \multicolumn{4}{|l|}{ Age, years } \\
\hline$>30^{\text {Reference }}$ & 1.0 & 1.0 & 1.0 \\
\hline$\leq 30$ & $1.677(0.877-2.769) ;<0.001^{*}$ & $2.321(1.122-3.767) ;<0.001^{*}$ & $1.976(0.875-3.211) ;<0.001^{*}$ \\
\hline \multicolumn{4}{|l|}{ Place of residence } \\
\hline Rural $^{\text {Reference }}$ & 1.0 & 1.0 & 1.0 \\
\hline Urban & 1.389 (0.744-2.119); 0.006* & $2.137(0.907-3.565) ;<0.001^{*}$ & $3.243(2.340-4.780) ;<0.001^{*}$ \\
\hline \multicolumn{4}{|l|}{ DM family history } \\
\hline Negative $^{\text {Reference }}$ & 1.0 & 1.0 & 1.0 \\
\hline Positive & 1.187 (0.543-1.965); 0.004* & $2.456(1.437-3.670) ; 0.015^{*}$ & 1.365 (0.678-2.010); 0.033* \\
\hline \multicolumn{4}{|l|}{ Season of diagnosis } \\
\hline Dry ${ }^{\text {Reference }}$ & 1.0 & 1.0 & 1.0 \\
\hline Rainy & $1.464(0.458-2.491) ; 0.001^{*}$ & $1.511(0.611-2.442) ; 0.001^{*}$ & 1.129 (0.401-1.910); 0.001* \\
\hline
\end{tabular}

TIDM, type 1 diabetes mellitus; OR, odds ratio; CI, confidence interval; LR, logistic regression; UUTH, University of Uyo Teaching Hospital. * Statistically significant. ${ }^{\text {a }}$ Former/present. 
are lower than the rate $(7.4,1,000)$ observed in the present study which indicates a high prevalence of adult-onset type 1 diabetes in Uyo, South-South Nigeria [10, 11].

\section{Gender Distribution}

The females predominated among the study cohorts and were more likely to be diagnosed with type 1 diabetes than their male counterparts, which is consistent with a recent report documented in Sri Lanka by Wijesuriya and colleagues [12]. However, contrary to our findings, a recent systematic review of the existing literature on adultonset type 1 diabetes by Diaz-Valencia and colleagues [13] concluded that adult-onset type 1 diabetes was more prevalent among the males than the females.

However, a gender-based pattern of type 1 diabetes has been observed to be of male preponderance in regions (Europe) of a high incidence of type 1 diabetes, whereas regions (Africa and Asia) with a low incidence report a female preponderance, which corroborates our finding [6]. The smaller muscle bulk needed for glucose uptake, the higher estrogen/progesterone status known to influence insulin sensitivity, and the greater propensity for autoimmune disorders seem to predispose the females to the higher incidence of type 1 diabetes $[14,15]$.

\section{Age Characteristics}

Most of the study cohorts were in their thirties at the time of diagnosis and age $\leq 30$ years was an independent predictor of type 1 diabetes in the present study. This pattern seems to fit into the age description of reported cases of adult-onset type 1 diabetes documented within the African region $[16,17]$. The majority of the Africans present a decade later, between 22 and 29 years, compared with the European descendants [16, 17]. Moreover, Africans have been reported to have a bimodal peak of the age of onset of type 1 diabetes; the first peak occurring between 14 and 17 years, and the second peak occurring around age $30[16,17]$.

The plausible reason for the late onset of type 1 diabetes among Africans is unknown but may be attributed to the prolonged breastfeeding practices, common in Africa, which reduces the introduction of cow's milk protein-containing bovine albumin known to trigger beta cell autoimmunity, thereby delaying the onset of type 1 diabetes [16]. Additionally, the presentation of females with type diabetes at a younger age compared with the males has been adduced to their earlier pubertal changes associated with post-pubertal endocrine and metabolic alterations affecting insulin sensitivity and resistance [18].

Pattern, Trend and Predictors of Adult-Onset Type 1 Diabetes

\section{Anthropometric Characteristics}

Unlike in type 2 diabetes and before insulin therapy in type 1 diabetes, changes in BMI status have never featured prominently as a characteristic of adult-onset type 1 diabetes. This cardinal feature of type 1 diabetes was observed in the present sample such that the overall cohort had a mean BMI within the normal range $(24.27 \pm 3.40)$, consistent with similar findings by Govender and colleagues [17] in South Africa. However, the mean BMI status among the females was significantly high compared to the males and was found to be in the overweight range $(26.30 \pm 4.25)$. Evidence suggests that higher BMI may accelerate beta cell destruction which may partly explain the younger age at diagnosis observed among the females in the present study who had higher BMI status than the males [17].

\section{Sociodemographic Characteristics}

Similar to a local report by Ekpeyong and colleagues [19], most of the subjects were urban-dwellers which significantly predicted type 1 diabetes among the entire cohorts and separately among the males and females. Being an urban-dweller may indicate a higher exposure rate to other environmental determinants involved in type $1 \mathrm{di}$ abetes pathogenesis, which have been observed to vary between the urban and rural settings [20].

To our knowledge and consistent with the present study, no relationship has been established between marital union and the onset of type 1 diabetes among the male and female adults. However, adult-onset type 1 diabetes is purported to impact negatively on the social, psychological, and medicals aspects of marital union as reviewed recently by Priya and colleagues [21, 22], adding more distress to the disease burden. In contrast, a recent population-based study documented in Brazil reported a significant association between marital union and diabetes mellitus among the general diabetes subjects [23].

Most of our cohorts were predominantly into small scale (petty) trading (a low occupational class) which fits into the major occupational class of educated adult inhabitants of the study region [24]. Our study also showed, albeit statistically insignificant, and increased likelihood of type 1 diabetes with low occupational status. Small scale trading indicates low-income level which is associated with enormous economic burden, and type 1 diabetes being a disease of significant financial burden, may impact negatively on these patients' financial capabilities to cope with type 1 diabetes care as reported $[25,26]$.

Higher educational status was associated with type 1 diabetes in the present sample, similar to the finding by

Dubai Diabetes Endocrinol J 2020;26:119-127 
Olssen and colleagues [27] who opined that high levels of education was associated with an increased risk of autoimmune (latent autoimmune diabetes in adults and type 1 diabetes) diabetes through increased risk of the nongenetic triggers of the disease. Higher educational status might prompt insufficient exposure to early infections which have been proposed to increase the risk of type 1 diabetes as the maturation of immune regulation after birth is driven by exposure to microbes $[6,28]$.

Though cigarette and alcohol consumption has long been associated with type 1 diabetes and its complications as extensively documented $[29,30]$. However, no such association existed in the present study which could be due to the limited number of the sample population to power the study to draw a firm conclusion. Family clustering of type 1 diabetes remains a conspicuous feature secondary to genetic predisposition but this has not been fully characterized among adults, especially among African descendants $[31,32]$.

The present study demonstrated that $23.5 \%$ of the cohorts, with male predominance, affirmed to having a positive type 1 diabetes family history in either a first- or second-degree relative, similar to the findings $(21.8 \%)$ documented by Parkkola and colleagues [31]. Furthermore, the likelihood of developing type 1 diabetes with a positive diabetes family was found to be higher among the females which corroborates recent findings reported by Krischer and colleagues [32] who demonstrated that females had a greater propensity to developing islet cell autoantibody and subsequent progression to type 1 diabetes than the males.

The majority were diagnosed during the rainy season which also predicted type 1 diabetes among study cohorts and separately among the males and females. This finding conforms to earlier reports documented in a Cameroonian study [33]. In that study conducted in almost similar Nigerian climate, without segregating type 1 diabetes and 2 diabetes, the authors reported the highest diabetes prevalence during the rainy season [33]. Furthermore, the authors had adduced their findings to a number of factors including (1) nutritional variability due to indoor cultures which increases hyperglycemic status and the emergence of diabetic symptoms and (2) an increase in viral and other infections known to trigger diabetes onset [33].

The strength of the study lies in its relative large sample size and being the first study on adult type 1 diabetes in the studied region. However, it was challenged by a number of factors worth mentioning. First, it is purely a hospital-based retrospective records review conducted in a single center that might not be representative of the general population; hence, it should be interpreted with cau- tion. Second, the autoantibodies and genetic marker that define type 1 diabetes were not considered due to a lack of relevant data occasioned by scarce resources in the study center which may lead to diabetes misclassification and/or misclassification in the current study.

\section{Conclusion}

The study revealed that the burden of type 1 diabetes was comparatively high within the studied region. However, the yearly prevalence exhibited dynamic fluctuations which could be a consequence of urban-rural migration, environmental, and other unidentified sociocultural factors within the studied population. The disproportionate distribution of the disease burden with a profound bias toward the females, urban-dwellers, age $\leq 30$, and the rainy season is valuable epidemiologic evidence for the design of type 1 diabetes-targeted preventive programs by various concerned stakeholders.

\section{Acknowledgements}

We sincerely appreciate the assistance of all the other resident doctors in the University of Uyo Teaching Hospital, Uyo, Nigeria during the conduct of this study.

\section{Statement of Ethics}

The study protocol was approved by the Research Ethics Committee of the Institution with approval reference UUTH/AD/S/96/ VOL.XX1/282.

\section{Conflict of Interest Statement}

The authors declare that they have no conflicts of interest to disclose.

\section{Funding Sources}

The authors received no funding for the study.

\section{Author Contributions}

All the authors were involved substantially in the concept and design of the study, acquisition, analysis and interpretation of the data, drafting the article, revising the article critically for its intellectual content, and in the final approval of the version to be published. 


\section{References}

1 Ogurtsova K, da Rochas Fernandez JD, Huang Y, Linnenkamp U, Guariguata L, Cho NH. IDF diabetes atlas: global estimate for the prevalence of diabetes for 2015 and 2040. Diabetes Res Clin Pract. 2017;128:40-50.

2 Dunachie S, Chamnan P. The double burden of diabetes and global infection in low and middle-income countries. Trans R Soc Trop Med Hyg. 2019;113(2):56-64.

3 Baynes HW. Classification, pathophysiology, diagnosis and management of diabetes mellitus. J Diabetes Metab. 2015;6:541.

4 Punthakee Z, Punthakee Z, Goldenberg R, Katz P. Definition, classification and diagnosis of diabetes, prediabetes and metabolic syndrome. Can J Diabetes. 2018;42(Suppl 1): S10-5.

5 Atkinson MA, Eisenbarth GS, Michels AW. Type 1 diabetes. Lancet. 2014;383(9911):6982.

6 Maahs DM, West NA, Lawrence JM, MayerDavis EJ. Epidemiology of type 1 diabetes. Endocrinol Metab Clin North Am. 2010;39(3): 481-97.

7 Monaghan M, Helgeson V, Wiebe D. Type 1 diabetes in young adulthood. Curr Diabetes Rev. 2015;11(4):239-50.

8 Uloko AE, Musa BM, Ramalan MA, Gezawa ID, Puepet FH, Uloko AT, et al. Prevalence and risk factors for diabetes mellitus in Nigeria: a systematic review and meta-analysis. Diabetes Ther. 2018;9(3):1307-16.

9 Campbell MJ. Statistics at square one. 9th ed. London: BMJ Publishing Group; 1997.

10 Menke A, Orchard TJ, Imperatore G, Bullard KM, Mayer-Davis E, Cowie CC. The prevalence of type 1 diabetes in the United States. Epidemiology. 2013;24(5):773-4.

11 Xu G, Liu B, Sun Y, Du Y, Snetselaar LG, Hu FB, et al. Prevalence of diagnosed type 1 and type 2 diabetes among the US adults in 2016 and 2017: population-based study. BMJ. 2018;362:K1497.

12 Wijesuriya MA, Sandy JL, Warnapura CL, Middlehurst AC, Ogle GD. Characteristics of insulin registry patients with type 1 diabetes in Sri Lanka. J Diabetol. 2019;10:37-40.
13 Diaz-Valencia PA, Bougnères $\mathrm{P}$, Valleron AJ. Global epidemiology of type 1 diabetes in young adults and adults: a systematic review. BMC Public Health. 2015;15:255.

14 Desai MK, Brinton RD. Autoimmune disease in women: endocrine transition and risk across the lifespan. Front Endocrinol. 2019; 10:265.

15 Kim K, Park SM. Association of muscle mass and fat mass with insulin resistance and the prevalence of metabolic syndrome in Korean adults: a cross-sectional study. Sci Rep. 2018; 8(1):2703.

16 Padoa C. The epidemiology and pathogenesis of type 1 diabetes mellitus in Africa. J Clin Endocrinol Metab. 2011;16(3):130-6.

17 Govender P, Elmezughi K, Esterhuizen T, Paruk I, Pirie FJ, Motala AA. Characteristics of subjects with diabetes mellitus diagnosed before 35 years of age presenting to a tertiary diabetes clinic in Durban, South Africa, from 2003 to 2016. J Clin Endocrinol Metab. 2018; 23(1):26-31.

18 Gillespie KM, Nolsøe R, Betin VM, Kristiansen OP, Bingley PJ, Mandrup-Poulsen T, et al. Is puberty an accelerator of type 1 diabetes in IL6-174CC females? Diabetes. 2005;54(4): 1245-8.

19 Ekpenyong CE, Akpan UP, Ibu JO, Nyebuk DE. Gender and age-specific prevalence and associated risk factors of type 2 diabetes mellitus in Uyo Metropolis, South Eastern Nigeria. Diabetol Croat. 2012;41:17-23.

20 Esposito S, Toni G, Tascini G, Santi E, Berioli MG, Principi N. Environmental factors associated with type 1 diabetes. Front Endocrinol. 2019; 10:592.

21 Priya G, Kalra B, Grewal E, Dardi IK. Premarriage counseling in type 1 diabetes. Indian $\mathrm{J}$ Endocrinol Metab. 2018 Jan-Feb;22(1):12631.

22 Khandelwal D, Gupta L, Kalra S, Vishwakarma A, Lal PR, Dutta D. Diabetes distress and marriage in type-1 diabetes. Indian J Community Med. 2018 Oct-Dec;43(4):316-9.

23 Flor LS, Campos MR. The prevalence of diabetes mellitus and its associated factors in the Brazilian adult population: a populationbased study. Rev Bras Epidemiol. 2017;20(1): 16-29.
24 Ekot GE. Small business ownership and management in Uyo metropolis, Akwa Ibom State, Nigeria: problems and prospects. Int J Econ Dev Res Invest. 2010;1(1):123-34.

25 Moucheraud C, Lenz C, Latkovic M, Wirtze $\mathrm{V}$. The cost of diabetes treatment in low- and medium-income countries: a systematic review. BMJ Global Health. 2019;4:e001258.

26 Mailo VJ, Best N, Cheal S, Kelly F, Turner J. Interplay between type 1 diabetes and occupation. Asian J Occup Ther. 2016;12:1-7.

27 Olssen L, Ahlbom A, Grill V, Midthjell K, Calsson S. High levels of education are associated with an increased risk of latent autoimmune diabetes in adults. Diabetes Care. 2011; 34(1):102-7.

28 Pundziute-Lycka A, Urbonate B, Dahlquist G. Infections and risk of type 1 (insulin-dependent) diabetes in Lithuanian children. Diabetologia. 2000;43:1229-34.

29 Campagna D, Alamo A, Di Pino A, Russo C, Calogero AE, Purrello F, et al. Smoking and diabetes: dangerous liasons and confusing relationships. Diabetol Metab Syndr. 2019;11: 85.

30 White ND. Alcohol use in young adults with type 1 diabetes mellitus. Am J Lifestyle Med. 2017 Nov-Dec;11(6):433-5.

31 Parkkola A, Härkönen T, Ryhänen SJ, Ilonen J, Knip M. Extended family history of type 1 diabetes and phenotype and genotype of newly diagnosed children. Diabetes Care. 2013; 36(2):348-54.

32 Thomas NJ, Jones SE, Weedon MN, Shields BM, Oram RA, Hattersley AT. Frequency and phenotype of type 1 diabetes in the first six decades of life: a cross-sectional, genetically stratified survival analysis from UK Biobank. Lancet Diabetes Endocrinol. 2018;6(2):1229.

33 Lontchi-Yimagou E, Tsalefac M, Tapinmene LMT, Noubiap JJN, Balti EV, Nguewa JL, et al. Seasonality in diabetes in Yaoundé, Cameroon: a relation with precipitation and temperature. BMC Public Health. 2016;16:470.
Pattern, Trend and Predictors of Adult-Onset Type 1 Diabetes
Dubai Diabetes Endocrinol J 2020;26:119-127 DOI: $10.1159 / 000511242$ 